\section{Commentary: Innovation favors the prepared mind}

\author{
Louis H. Stein, MD, PhD, and Sanjay Samy, MD
}

Reoperative cardiac surgery gives surgeons justifiable pause. In some case series, injury at the time of reentry can carry up to a $25 \%$ mortality. ${ }^{1}$ Preoperative computed tomographic imaging, essential in establishing an operative strategy, can forewarn us of potential dangers (such as an adherence of the aorta or right ventricle to the posterior sternal table or a sternal wire abutting the ascending aorta), but it cannot predict the occurrence of a catastrophic complication. An ill-timed entry into the aorta or other cardiac chamber can result in devastating hemorrhage, with insufficient dissection to provide a tension free-repair.

A thoughtful preoperative approach is critical in the safe conduct of these operations. LaPar and associates ${ }^{2}$ reported that initiating an institutional protocol including these strategies reduced the rate of injury on reoperation. Their protocol included preoperative computed tomographic angiography with preparation for the initiation of peripheral cardiopulmonary bypass $(C P B)$ if needed. CPB permits decompression of the heart. This permits nonadherent cardiac structures to fall away from the sternum. Bleeding from injury to the right ventricle can also be reduced while on $\mathrm{CPB}$, facilitating a safe repair.

Even with these safeguards, however, injury to an adherent aorta can result in impossible-to-control exsanguination. Dense adhesions may prevent placing a crossclamp. To address this, some have advocated systemic cooling on peripheral CPB first, then performing the sternotomy with hypothermia at low flow or under circulatory arrest. ${ }^{3}$ Use of hypothermia adds time to the case for requisite cooling, in addition to adding concerns regarding coagulopathy. The total time that a patient can safely tolerate circulatory arrest is limited. ${ }^{4}$ The intended complex aortic procedure may also require an interval of circulatory arrest, further adding time pressures. This technique also raises concern for myocardial protection during ventricular fibrillation should

From the Division of Cardiothoracic Surgery, Albany Medical College, Albany, NY. Disclosures: Authors have nothing to disclose with regard to commercial support.

Received for publication Oct 15, 2019; revisions received Oct 15, 2019; accepted for publication Oct 16, 2019; available ahead of print Oct 31, 2019.

Address for reprints: Louis H. Stein, MD, PhD, Division of Cardiothoracic Surgery, Albany Medical Center, Surgeons Pavilion, 3rd Floor, 50 New Scotland Ave, Al-

bany, NY 12208 (E-mail: steinl1@amc.edu).

J Thorac Cardiovasc Surg 2021;161:1731

$0022-5223 / \$ 36.00$

Copyright (C) 2019 by The American Association for Thoracic Surgery

https://doi.org/10.1016/j.jtcvs.2019.10.082

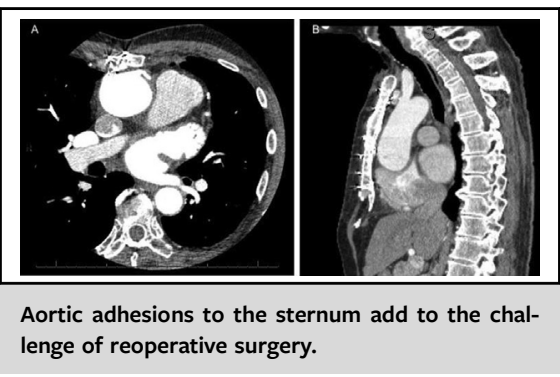

CENTRAL MESSAGE

Innovations designed for minimally invasive surgery can make for safer reoperative aortic surgery.

aortic insufficiency be present and ventricular decompression be impossible.

In this issue of the Journal, Mehta and colleagues 5 report the addition of percutaneous retrograde cardioplegia and endovascular balloon placement to the resternotomy with cardiopulmonary bypass. By taking these procedures to the hybrid operating room, they have utilized tools designed initially for minimally invasive surgery. In doing so, they can safely "clamp" the aorta, while arresting and protecting the heart before sternotomy. We congratulate them on their formulation of this clever design and successful outcomes on these difficult cases. Although theirs is a useful technique, patients requiring its use will certainly each pose unique challenges. We would also like to point out the importance of team planning in these interesting cases. The additions of percutaneous cardioplegia and endovascular balloon aortic clamping both require additional expertise from team members away from the operative field. Effective team communication and understanding are critical to the safe application of sophisticated technology for these sick patients.

\section{References}

1. Park CB, Suri RM, Burkhart HM, Greason KL, Dearani JA, Schaff HV, et al. Identifying patients at particular risk of injury during repeat sternotomy: analysis of 2555 cardiac reoperations. J Thorac Cardiovasc Surg. 2010;140:1028-35.

2. LaPar DJ, Ailawadi G, Harris DA, Hajzus VA, Lau CL, Kern JA, et al. A protocoldriven approach to cardiac reoperation reduces mortality and cardiac injury at the time of resternotomy. Ann Thorac Surg. 2013;96:865-70; discussion 870.

3. Möller F, Liska J, Lockowandt U, Samuelsson S, Franco-Cereceda A. Resternotomy using hypothermic arrest. J Card Surg. 2010;25:272-6.

4. Geube M, Sale S, Svensson L. Con: routine use of brain perfusion techniques is not supported in deep hypothermic circulatory arrest. J Cardiothorac Vasc Anesth 2017;31:1905-9.

5. Mehta AR, Hammond B, Unai S, Navia JL, Gillinov M, Pettersson G Percutaneous cardioplegic arrest before repeat sternotomy in patients with retrosternal aortic aneurysm. J Thorac Cardiovasc Surg. 2021;161:1724-30. 